\title{
Impacts of simulated overfishing on the territoriality of coral reef damselfish
}

\author{
Daniela M. Ceccarellii ${ }^{1 *}$, Terry P. Hughes ${ }^{1}$, Laurence J. McCook ${ }^{2,3}$ \\ ${ }^{1}$ Centre for Coral Reef Biodiversity, School of Marine Biology and Aquaculture, James Cook University, \\ Townsville, Queensland 4811, Australia \\ ${ }^{2}$ Australian Institute of Marine Science, PMB3, Townsville, MC, Queensland 4810, Australia \\ ${ }^{3}$ Present address: Great Barrier Reef Marine Park Authority, PO Box 1379, Townsville, Queensland 4810, Australia
}

\begin{abstract}
The loss of large fishes from coral reefs can alter the composition of benthic assemblages and increase the abundance of smaller fishes at lower trophic levels. An experimental exclusion of medium and large fishes, maintained over $30 \mathrm{mo}$, had a major impact on the dynamics of 2 abundant damselfishes (Pomacentrus adelus and P. wardi) and altered their relative abundance in favour of the larger species, $P$. wardi. The territory size of both species inside exclusion cages increased by 20 to $50 \%$ in the first year, but then declined to their original size after a further 6 mo. The exclusion of larger fishes also led to an increase in the quantity and quality of food algae within damselfish territories. These results suggest that larger predatory and herbivorous fish influence the composition of coral reef communities not only directly, but also indirectly, by controlling the abundance and territorial activities of damselfish.
\end{abstract}

KEY WORDS: Territorial damselfish · Herbivores · Cage experiment · Trophic cascade · Overfishing

\section{INTRODUCTION}

The overexploitation of fish stocks dramatically alters the trophodynamics and community structure of coral reef ecosystems (Hughes 1994, McClanahan et al. 1999, Birkeland 2004). The removal of larger predators and competitors alters trophic structures, often leading to increased populations of prey species (Steneck 1998). The extent of overfishing effects is difficult to quantify, due to a lack of existing baseline data on 'pre-impact' food webs (Steneck 1998, Hughes et al. 2005). Recently, comparisons between areas open and closed to fishing have shown that overexploitation by humans can cause 'trophic cascades', where marine communities become dominated by lower trophic levels (e.g. Sala et al. 1998, McClanahan et al. 1999).

A primary concern for coral reefs is the loss of medium-to-large herbivores, which maintain coral dominance by reducing algal biomass (Hay 1981, Hughes 1994, McCook 1996, 1999, Hughes et al. 1999).
In the Caribbean, East Africa and elsewhere, sea urchins have become the major herbivores, following the depletion of larger herbivorous fish (e.g. Hay 1984, Hughes 1994). Similarly, a recent study on coral reefs off Tanzania demonstrated increased abundances of some species of territorial damselfish in areas subject to fishing (McClanahan et al. 1999). Given the specialized and spatially restricted feeding mode of territorial damselfish, these fish are unlikely to have the same ability to reduce algal biomass as the larger roving herbivores (Steneck 1988, Hixon 1996). Further, some damselfish may actively promote the growth of algal turf (Sammarco \& Carleton 1981, Ceccarelli et al. 2001, Hata \& Kato 2003).

Territorial damselfish have a major influence on the biomass, productivity and composition of algae within their territories (Lassuy 1980, Hata \& Kato 2002). In some cases, they can also be major determinants of the structure of coral communities (Wellington 1982, Hixon \& Brostoff 1996, Ceccarelli et al. 2001). Interac- 
tions between territorial damselfish and larger fishes usually take the form of either predation on damselfish or the aggressive exclusion of roving herbivores by territorial damselfish (Ceccarelli et al. 2001). However, the effects of predation or competition from larger fishes on territorial damselfish are not completely understood (Ceccarelli et al. 2005).

In territorial organisms, population density is usually closely related to territory size, with larger territory sizes leading to lower population densities (Grant 1997). If energy expenditure restricts the size of territories that damselfish are able to defend, then the presence of larger, roving competitors should reduce the size of territories and increase damselfish population densities (Hixon 1980). Predation and competition by larger fishes also have the potential to affect the relative abundance of sympatric damselfish species, since some are likely to be more robust to the effects of competition and predation than others.

The ability of damselfish to 'cultivate' algal turfs of high food quality may be affected by the need to defend their territories from larger herbivores. Furthermore, grazing inside damselfish territories by larger herbivores can directly reduce food quantity and alter the composition of algae inside territories (Ceccarelli et al. 2005). Consequently, larger herbivores can influence algal assemblages within damselfish territories both directly and indirectly (Robertson et al. 1976).

Here, we used the experimental exclusion of medium and large fishes to test the effects of simulated overfishing on territorial damselfish. The experiment mimics the widespread removal of both predatory and herbivorous fish by heavy subsistence fishing. Specifically, we test the following 3 hypotheses about the exclusion of medium and large fishes: (1) it lowers the densities of territorial damselfishes; (2) it will cause an increase in damselfish territory size; (3) and it will increase the percent cover of palatable algae inside damselfish territories.

\section{MATERIALS AND METHODS}

The fish exclusion experiment was established on the landward side of the reef crest zone of Pioneer Bay, Orpheus Island, Great Barrier Reef $\left(18^{\circ} 36^{\prime} \mathrm{S}\right.$, $146^{\circ} 29^{\prime} \mathrm{E}$ ) in October 2000. Cages that excluded larger fishes, but included pre-established adult territorial damselfish and subsequent recruits, were constructed and maintained for over 30 mo. During the experiment (between October 2000 and August 2003), the coral community on the Pioneer Bay reef was recovering from a massive coral bleaching event that took place in 1998 (Marshall \& Baird 2000), and the substrate was occupied primarily by dead coral surfaces covered in closely cropped algal turfs (Diaz-Pulido \& McCook 2002). Here, we focus on the responses of 3 territorial damselfish species that are abundant in this reef zone: Hemiglyphidodon plagiometapon, Pomacentrus wardi and $P$. adelus. The habitat of $H$. plagiometapon forms a band extending approximately $5 \mathrm{~m}$ landward and $3 \mathrm{~m}$ seaward of the reef crest. The 2 smaller and slightly less aggressive species, $P$. wardi and $P$. adelus, are distributed further shorewards across the reef flat. Of the latter 2 species, $P$. wardi is usually larger and more aggressive than $P$. adelus (D. M. Ceccarelli unpubl. data). Because of its low abundance relative to the other 2 species, $H$. plagiometapon was only considered in the analyses for territory composition; comparisons of density and territory size were only made for $P$. wardi and $P$. adelus.

The experiment encompassed 3 treatments: (1) caged plots that excluded larger fishes, (2) partial cages to control for cage artefacts and (3) open plots. Each treatment had 4 replicates. Fully caged plots excluded fish wider than $2 \mathrm{~cm}$, while partially caged plots allowed access to all fish. Cages, partial cages and open plots measured $5 \times 5 \mathrm{~m}$, and were placed approximately $10 \mathrm{~m}$ apart. The sides of the full and partial cages were constructed of plastic mesh $(1 \times$ $1 \mathrm{~cm}$ for the bottom $2 \mathrm{~m}$, and $2 \times 2 \mathrm{~cm}$ for the top $1.5 \mathrm{~m}$ ) on a frame of galvanized steel pipes. Half of each side of the partial cages was enclosed in mesh. Cages and partial cages were unroofed and $3.5 \mathrm{~m}$ high in order to break the water surface at the highest high tide. Full cages were fitted with doors, so that sampling could be conducted inside the cages. The depth of the cages changed with the tides, and ranged from $\sim 0.5 \mathrm{~m}$ to just under $3.5 \mathrm{~m}$. Open, partially caged and fully caged plots were interspersed 7 to $10 \mathrm{~m}$ apart, along a line parallel to the reef crest. The experiment commenced in October 2000, and the mesh was removed from cages and partial cages in May 2003 (Month 31), with final data collected in August 2003 (Month 34). To prevent fouling, the mesh was cleaned by scrubbing approximately every $10 \mathrm{~d}$ throughout the experiment. The benthic community structure inside fish-exclusion cages experienced a dramatic phase shift from coral/turf dominance to an assemblage dominated by large fleshy macroalgae up to $3 \mathrm{~m}$ high (primarily Sargassum spp.; Fig. 1).

Densities of damselfish and their territory size were censused from November 2000 (Month 1) to August 2003 (Month 34), at intervals of between 4 and $10 \mathrm{wk}$. At each census, damselfish were counted in all the plots, with recruits and adults recorded separately. Fish counted as recruits were those which still bore a distinctive colouration which was different from that of 


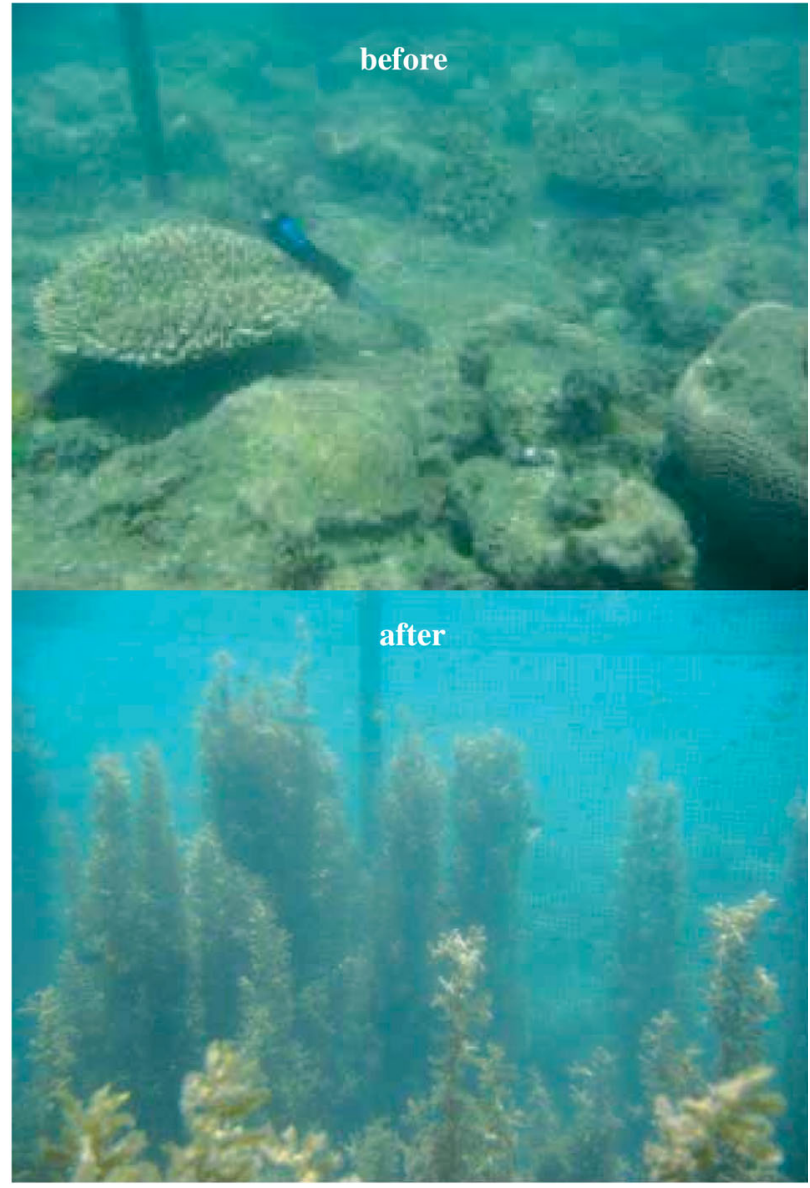

Fig. 1. Benthic communities on the reef crest of Pioneer Bay before and after the exclusion cages were established. Communities in the partial cages remained much like those in the open plots, which are well represented by the 'before' picture. Photographs supplied by L. J. McCook

juveniles and adults. Three territories per species were randomly selected in each plot ( 3 territories $\times 4$ plots $\times$ 2 species $=24$ territories treatment ${ }^{-1}$ ), and the resident damselfish were observed for $15 \mathrm{~min}$ periods to determine the territory boundaries. Territory circumference was measured after placing lead weights around the territory boundaries during the observation period. Territory area was estimated by measuring the circumference of each territory and using the formula for a circle of equivalent circumference.

At each sampling date, algal assemblages were sampled inside and outside the territories of the 3 damselfish species (Pomacentrus wardi, P. adelus and Hemiglyphidodon plagiometapon). Eight samples per species per treatment were taken haphazardly at each census ( 4 inside and 4 outside $\times 3$ species $\times 3$ treatments $=72$ samples). Overall, 1080 algal samples were collected. All samples were collected from $3 \times 3 \mathrm{~cm}$ plots on smooth substrata, generally dead massive
Porites spp., to avoid differences in algal turf due to topographic complexity. Samples were collected by scraping turf off the substratum into a stocking using suction, then preserved in $10 \%$ formalin.

To estimate the relative abundance of different algal groups, samples were examined under a dissecting microscope using a grid with $1 \mathrm{~cm}$ squares over a Petri dish. The identity of the algae under 45 random intercepts was recorded to estimate percent cover in the Petri dish. To compare food quality inside and outside damselfish territories, we estimated the relative abundance of 2 genera commonly used by territorial damselfish as food: Polysiphonia spp., a group of filamentous red algae, and Hypnea spp., a delicate corticated red alga. Both algal taxa are commonly found in damselfish territories and in their guts (Lassuy 1980, Ceccarelli 2004), while other common algal turf taxa present in Pioneer Bay (e.g. Galaxaura spp., Gelidiopsis spp., Padina spp.) are considered less palatable (Barnes \& Devereux 1984, Ceccarelli 2004).

Changes in damselfish densities and territory sizes were compared across treatments and over time using repeated-measures ANOVA. Changes over time in algal abundance and taxonomic composition were compared across treatments, and inside versus outside territories. These comparisons were tested with nested repeated-measures ANOVA. Assumptions of normality (Levene's test), homogeneity of variance (predicted vs residual plots) and sphericity (Mauchley sphericity test) were tested before all ANOVAs, and no transformations were necessary.

\section{RESULTS}

\section{Damselfish density and territory size}

The densities of adult Pomacentrus wardi and $P$. adelus changed significantly in response to the exclusion of larger fishes (Table 1). In the cages, the density of $P$. wardi increased by over $100 \%$ (Fig. 2a), while $P$. adelus densities declined by more than $50 \%$ (Fig. 2b). These density shifts did not occur in open plots, while in partial cages density shifts were intermediate between open and caged plots. When the mesh on cages was removed after 31 mo, differences between treatments disappeared within 8 wk (Fig. 2a,b).

Densities of recruits of the 2 damselfish species also differed significantly among treatments (Table 1). Open plots and partially caged plots received double the numbers of Pomacentrus adelus recruits than $P$. wardi recruits in both the recorded recruitment seasons (Months 13 and 25). In the second summer of the 
Table 1. Results of repeated-measures ANOVA on densities of adult and recruit Pomacentrus wardi and P. adelus, and their territory sizes. The 'value' column denotes the result of the multivariate statistic used in each analysis: ${ }^{*}$ Pillai's trace, ${ }^{* *}$ Wilks's lambda. Significant results are shown in bold

\begin{tabular}{|c|c|c|c|c|c|}
\hline Effect & Source of variation & Value & $\mathrm{df}$ & $F$ & $\mathrm{p}$ \\
\hline Adult damselfish density & Time $\times$ Treatment $\times$ Species & $0.001^{* *}$ & 32 & 2.429 & 0.009 \\
\hline Recruit damselfish density & Time $\times$ Treatment $\times$ Species & $1.970^{*}$ & 32 & 16.187 & $<0.001$ \\
\hline \multirow[t]{3}{*}{ Territory size } & Time $\times$ Treatment & $0.725^{*}$ & 26 & 2.405 & 0.001 \\
\hline & Time $\times$ Species & $0.353^{*}$ & 13 & 2.262 & 0.018 \\
\hline & Time $\times$ Treatment $\times$ Species & $0.366^{*}$ & 26 & 0.947 & 0.544 \\
\hline
\end{tabular}
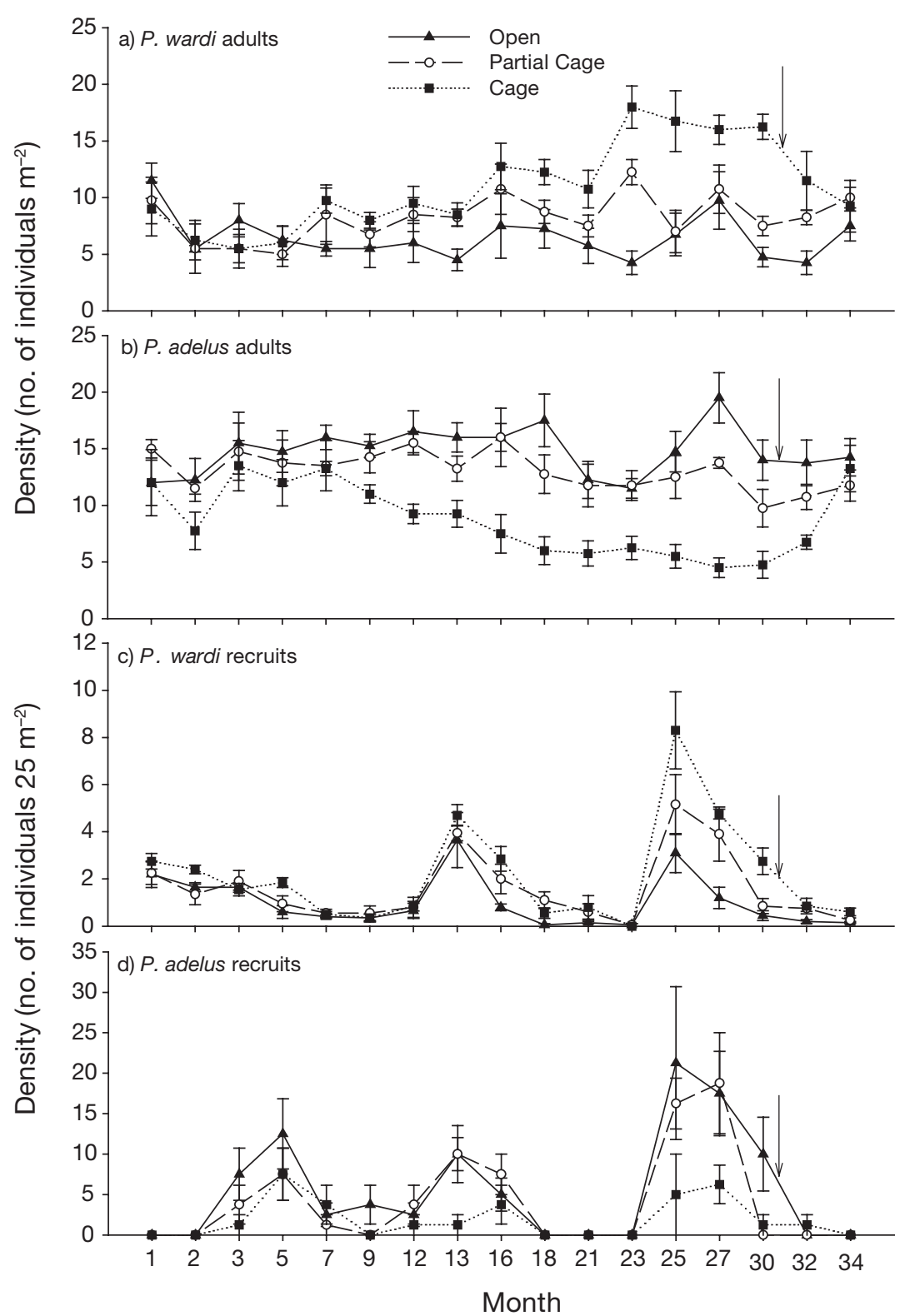

Fig. 2. Pomacentrus adelus, $P$. wardii. Densities of $(\mathrm{a}, \mathrm{b})$ adults and $(\mathrm{c}, \mathrm{d})$ of recruit numbers over time in the 3 treatments. Arrows show when the mesh on the cages was removed. Note the differences in the $y$-axes. Error bars $=1 \mathrm{SE}$ experiment (Month 25), double the numbers of $P$. wardi recruited in the cages than in open plots and partial cages (Fig. 2c), while $P$. adelus recruitment was $50 \%$ lower in the cages compared with partial cages and open plots during both summers (Fig. 2d).

In the cages, there was a small but statistically significant increase in the territory sizes of both species (Table 1). The territories of Pomacentrus wardi increased by a maximum of $25 \%$, while those of $P$. adelus increased by more than $40 \%$ (Fig. 3). The territory sizes of both species were highest in the cages, reaching their largest size 12 mo after the beginning of the experiment (Fig. 3). Overall, within the 31 mo of the experiment, this 5 mo period was the only time the territories of both damselfish species responded to the exclusion of larger fishes. Territories of $P$. wardi remained significantly larger than those of $P$. adelus (mean $\pm \mathrm{SE}=1.27 \pm 0.09 \mathrm{~m}^{2}$ and $0.97 \pm 0.06 \mathrm{~m}^{2}$, respectively) throughout the duration of the experiment.

\section{Relative abundance of edible algae in damselfish territories}

Food quality inside damselfish territories, estimated as the relative abundance of algae of the genera Polysiphonia spp. and Hypnea spp., was significantly affected by fish exclusion (Table 2). The relative abundance of Polysiphonia spp. inside the cages, both inside and outside damselfish territories, became significantly higher than in partially caged or open plots 


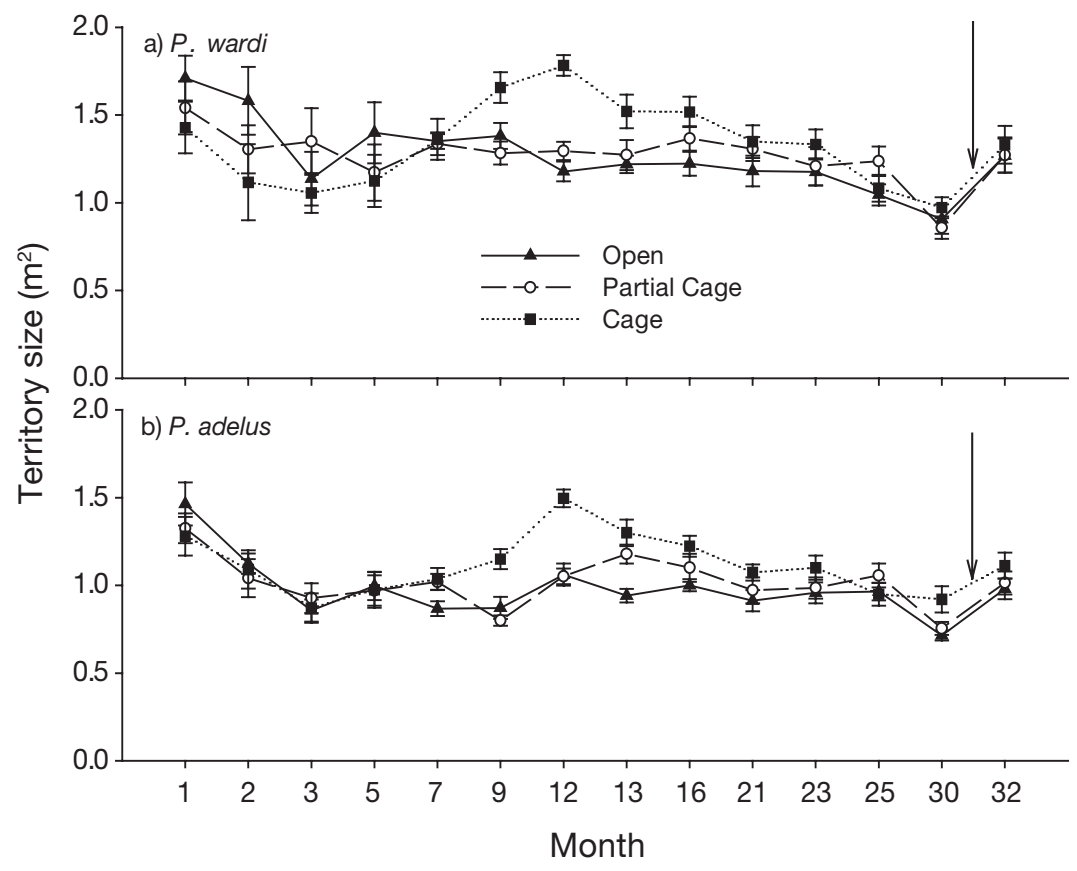

Fig. 3. Pomacentrus adelus, $P$. wardii. Territory area over time of the 2 numerically dominant damselfish species. Arrows and error bars as in Fig. 2 cating different temporal dynamics inside the territories of each species. In open plots, Polysiphonia spp. was most abundant inside Hemiglyphidodon plagiometapon territories until April 2002 (Month 18), when Pomacentrus wardi territories briefly had more Polysiphonia spp. (Fig. 4b). In the cages, the relative abundance of Polysiphonia spp. rapidly increased in the first few months of the experiment, especially inside $P$. wardi territories (Fig. 4c). After March 2001 (Month 4); however, Polysiphonia spp. was generally more abundant in the cages that in open plots (Fig. 4a), both inside and outside damselfish territories (Fig. 4c).

The relative abundance of Hypnea spp. was slightly higher in the cages in the latter half of the experiment, and then it bloomed in April 2003 (Month 30), just before the cages were removed (Fig. 5a). Generally, the highest abundance of Hypnea spp. and Polysiphonia spp. was found inside Hemiglyphidodon plagiometapon territories (Figs. 4b \& 5b). The largest increase in the abundance of Hypnea spp. occurred in the cages, inside damselfish territories (Fig. 5c). In the spring of 2001 (Month 12) and the autumn of 2003 (Month 30), Hypnea spp. blooms were found only inside $H$. plagiometapon territories, while it was significantly more abundant in Pomacentrus adelus territories than anywhere else in the winter of 2002 (Month 21).

Table 2. Results of nested repeated-measures ANOVA on abundance of algal turf and relative abundance of Polysiphonia spp. and Hypnea spp. collected within the territories of Pomacentrus wardi, P. adelus and Hemiglyphidodon plagiometapon, within and outside territories. 'Position' refers to whether samples were collected from within or outside territories. The 'values' column shows the result of the multivariate statistic used in each analysis. Significant results are shown in bold

\begin{tabular}{|c|c|c|c|c|c|}
\hline Effect & Source of variation & Value & df & $F$ & $\mathrm{p}$ \\
\hline \multirow[t]{5}{*}{ Turf abundance } & Time $\times$ Treatment & 1.100 & 28 & 3.664 & \\
\hline & Time $\times$ Species & 0.790 & 28 & 1.959 & \\
\hline & Time $\times$ Position (Treatment) & 1.026 & 42 & 1.597 & \\
\hline & Time $\times$ Treatment $\times$ Species & 1.405 & 56 & 1.701 & 0.005 \\
\hline & Time $\times$ Species $\times$ Position (Treatment) & 1.479 & 84 & 1.075 & 0.392 \\
\hline \multirow[t]{5}{*}{ Polysiphonia spp. } & Time $\times$ Treatment & 0.738 & 28 & 1.753 & 0.026 \\
\hline & Time $\times$ Species & 0.766 & 28 & 1.861 & 0.016 \\
\hline & Time $\times$ Position (Treatment) & 1.038 & 24 & 1.624 & 0.021 \\
\hline & Time $\times$ Treatment $\times$ Species & 0.758 & 56 & 0.734 & 0.911 \\
\hline & Time $\times$ Species $\times$ Position (Treatment) & 1.344 & 84 & 0.948 & 0.606 \\
\hline \multirow[t]{5}{*}{ Hypnea spp. } & Time $\times$ Treatment & 0.871 & 28 & 2.316 & \\
\hline & Time $\times$ Species & 0.737 & 28 & 1.751 & \\
\hline & Time $\times$ Position (Treatment) & 1.302 & 42 & 2.355 & \\
\hline & Time $\times$ Treatment $\times$ Species & 1.420 & 56 & 1.731 & $\mathbf{0 . 0 0 4}$ \\
\hline & Time $\times$ Species $\times$ Position (Treatment) & 1.966 & 84 & 1.601 & 0.003 \\
\hline
\end{tabular}



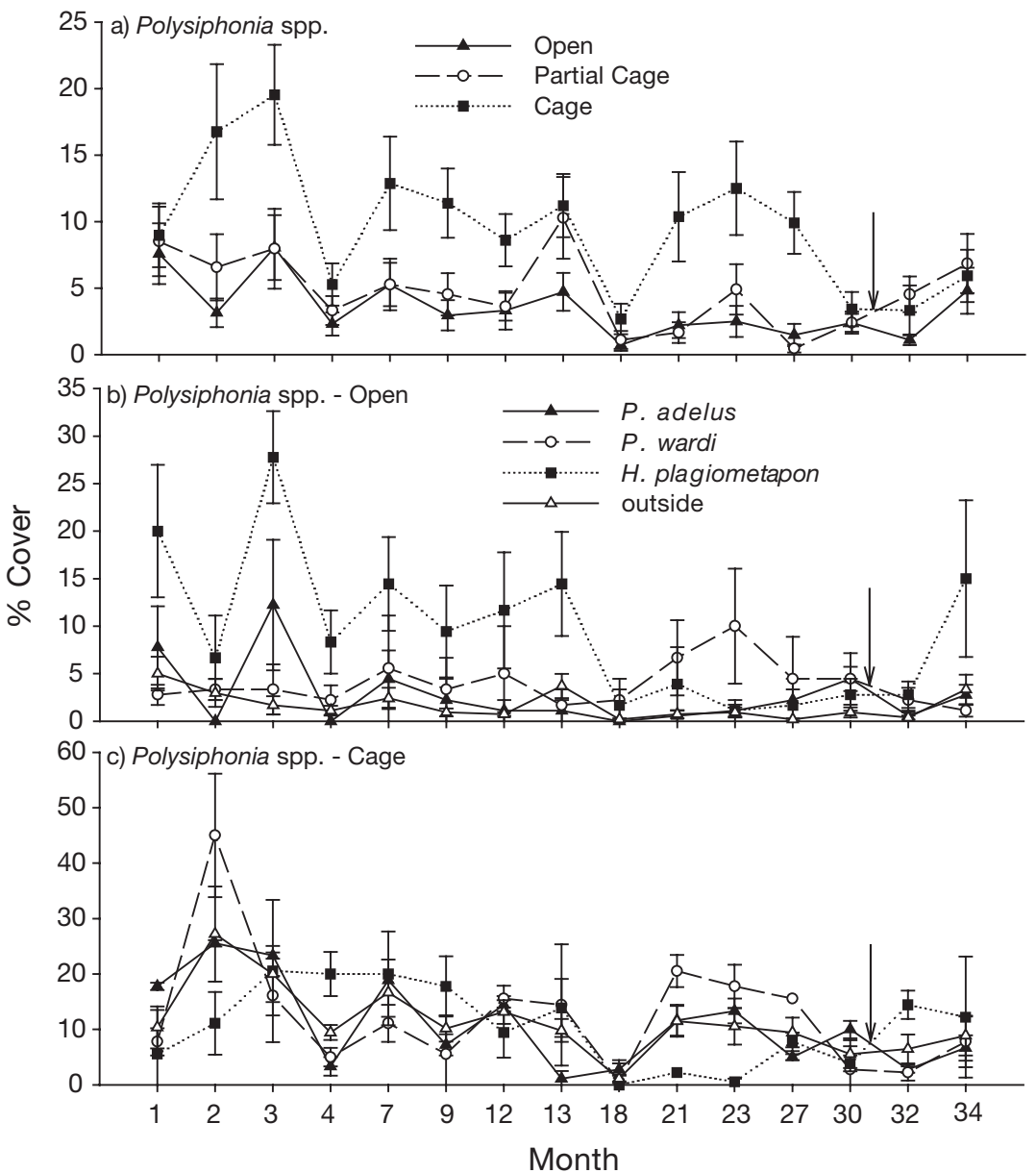

Fig. 4. Polysiphonia spp. Relative abundance of Polysiphonia spp. in (a) the 3 treatments, with samples from within and outside territories pooled; (b) in open plots outside and within the territories of the 3 damselfish species; and (c) in caged plots outside and within the territories of the 3 damselfish species. Values for outside territories have been pooled in (b) and (c) for clarity. Values for partial cages were not significantly different from open plots and are not shown here. Arrows and error bars as per Fig. 2. Note differences in the $y$-axes

\section{DISCUSSION}

This study provides the first experimental evidence that territorial damselfish populations and the composition of their territories respond to the depletion of larger fishes. The changes in damselfish populations and their territories inside of fish-exclusion cages may have been caused by 3 possible mechanisms. Firstly, the exclusion of predators by the cages may have differentially reduced predation on both adult and recruiting damselfish, thereby shifting the relative densities of Pomacentrus wardi and P. adelus. Secondly, cages reduced competition from larger roving herbivores, potentially increasing competition between $P$. wardi and $P$. adelus in favour of the larger species ( $P$. wardi). Thirdly, removing access by larger fishes caused a significant shift in habitat structure (from 2-dimensional coral/ turf dominance to 3-dimensional Sargassum spp. forests), creating an environment more suitable to $P$. wardi and to certain algal turf taxa. All 3 explanations imply that the observed changes were caused by the exclusion of larger fishes, either directly (reduced predation or competition between roving herbivores and damselfish) or indirectly (habitat shift through decreased herbivory).

While recruitment patterns of Pomacentrus adelus and $P$. wardi were significantly affected by the exclusion cages (which possibly acted as a visual barrier to some recruits), adult densities changed 6 mo before any new recruitment occurred. Therefore, changes in recruitment alone cannot entirely account for the significant shift in adult densities although they presumably contributed to the persistence of the longer-term numeric dominance of $P$. wardi in the cages. The increase in $P$. wardi densities in the cages occurred concurrently with a massive growth inside the cages of Sargassum spp., a fleshy macroalga that is usually absent from the Pioneer Bay reef crest. Adult and juvenile $P$. wardi inhabit beds of Sargassum spp. at other locations on the inner Great Barrier Reef (Lewis 1999, Ceccarelli 2004), so it is possible that the changes in $P$. wardi abundance were habitat driven. Large stands of fleshy macroalgae in the cages may also have created a less-favourable habitat for adult and juvenile $P$. adelus. Although there is no direct evidence, it seems likely that the effect of larger fishes, and roving herbivores in particular, on territorial damselfish populations lies at least partially in their ability to modify the habitat to the benefit of some damselfish species and the detriment of others.

The effects of caging on territory size were short lived. The absence of a persistent change in territory size in the fish-exclusion cages could be a product of 3 potential processes. Firstly, despite a significant increase in the territory size of Pomacentrus adelus and $P$. wardi in the cages, the elevated adult density of $P$. wardi may have eventually driven territory size to decrease. Secondly, the increase in 3-dimensional space availability presented by tall, erect Sargassum spp. plants may have reduced the need for a shortterm 2-dimensional expansion in territory area. 


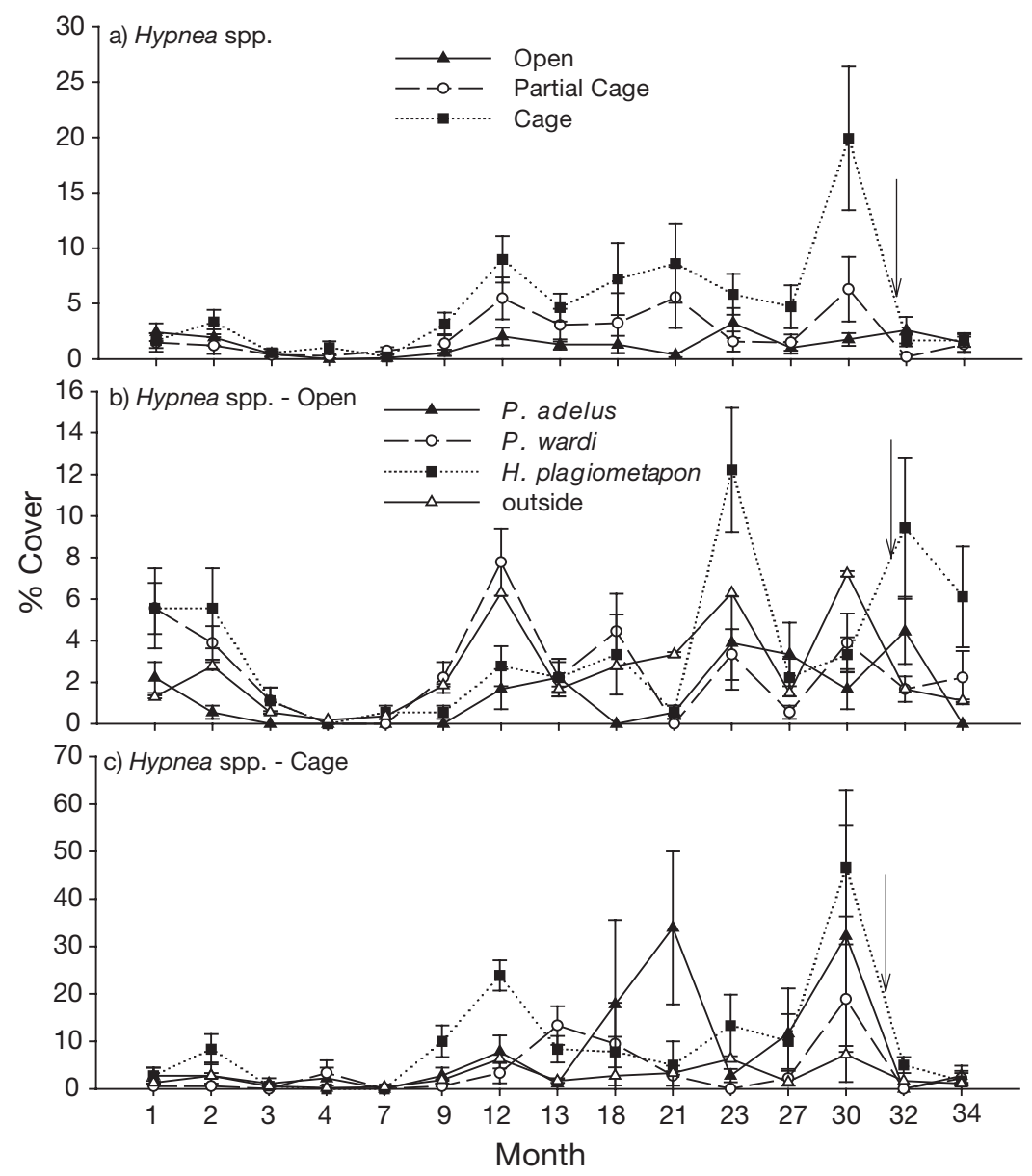

Fig. 5. Hypnea spp. Relative abundance of Hypnea spp. in (a) the 3 treatments, with samples from within and outside territories pooled, (b) in open plots outside and within the territories of the 3 damselfish species and (c) in caged plots outside and within the territories of the 3 damselfish species. Values for outside territories have been pooled in (b) and (c) for clarity. Partial cages were omitted as in Fig. 4. Arrows and error bars as per Fig. 2. Note differences in the $y$-axes

smaller territories restricted by increased intrusion pressure, which in turn is driven by high food quality (Schoener 1983). If damselfish were as effective at excluding competitors as a cage, we would expect no increase in food quantity as a result of caging. An increase in food quantity in the cages suggests that the defence of food resources by damselfish is not as effective as the defence provided by an exclusion cage. This conclusion seems reasonable because schooling in roving herbivores allows them to periodically invade damselfish territories (Robertson et al. 1976, authors' pers. obs.).

The relative abundance of Polysiphonia spp., a widely preferred food alga (Lassuy 1980, Santana 2001), increased inside the cages, especially inside damselfish territories. Even in the territories of Hemiglyphidodon plagiometapon, a detritivore, filamentous algae can serve the purpose of trapping detritus and can therefore be considered desirable (Wilson \& Bellwood 1997). Corticated red algae such as Hypnea spp. are also often found growing in damselfish territories (Lassuy 1980, Ferreira et al. 1998, Ceccarelli et al. 2005). Territories of H. plagiometapon and Pomacentrus adelus were occupied by up to 47 and $34 \%$ (respectively) by Hypnea spp. in the cages, compared with seasonal peaks of 10 and $4 \%$ (respectively) in open plots. This suggests that the invasions of larger herbivores affect the

Thirdly, the dominant competitive influence on territory size may have occurred primarily between the 2 congeneric damselfish (Bay et al. 2001), rather than between damselfish and roving herbivores. It is likely that a combination of the first and third processes was responsible for the observed patterns, because there was an increase in the 3-dimensional space available, and there was frequent aggression between $P$. wardi and $P$. adelus (authors' pers. obs.).

The quantity and quality of food resources in damselfish territories was highest inside cages. Algal turf abundance was higher inside all damselfish territories than outside, in accordance with the results of most studies on damselfish territories on heavily grazed reefs (Ceccarelli et al. 2001). In competition theory models (e.g. Davies 1978, Schoener 1983), there is a trade-off between the defence of large territories that compensate for low food quality and the defence of ability of some damselfish species to promote or cultivate palatable algae such as Polysiphonia spp. and Hypnea spp..

The absence of large herbivores often causes reef degradation (Hughes 1994, Hughes et al. 1999, McCook 1999) through the loss of top-down control on fleshy macroalgae. Further detrimental effects could result from situations where the overexploitation of large herbivores causes shifts in the relative abundance of territorial damselfish towards larger damselfish (eg. from Pomacentrus adelus to P. wardi) that promote thicker algal turfs in their territories (Ceccarelli et al. 2001). The occupation of larger proportions of reef substrata by larger damselfish could exacerbate reef decline through the detrimental effects of thick algal turfs, including the trapping of sediment, the smothering of reef-building corals and coralline algae, and the inhibition of coral recruitment (Sammarco \& 
Carleton 1981, Birrell et al. 2005). The removal of medium and large fishes can therefore influence not only damselfish populations, but also modify the overall effects of territorial damselfish on benthic assemblages.

Acknowledgements. This experiment was supported by grants from the Australian Research Council to T.P.H. We thank members of the Centre for Coral Reef Biodiversity and countless volunteers from James Cook University for the construction and maintenance of the cages. This manuscript benefitted from comments by Dr A. Baird and Dr G. P. Jones.

\section{LITERATURE CITED}

Barnes DJ, Devereux MJ (1984) Productivity and calcification on a coral reef: a survey using $\mathrm{pH}$ and oxygen electrode techniques. J Exp Mar Biol Ecol 79:213-231

Bay LK, Jones GP, McCormick MI (2001) Habitat selection and aggression as determinants of spatial segregation among damselfish on a coral reef. Coral Reefs 20:289-298

Birkeland C (2004) Ratcheting down the coral reefs. BioScience 54:1021-1027

Birrell CL, McCook LJ, Willis BL (2005) Effects of algal turfs and sediment on coral recruitment. Mar Pollut Bull 51: 408-414

Ceccarelli DM (2004) Herbivorous fishes as determinants of the structure of coral reef communities: farmers, foragers and their interactions. PhD thesis, James Cook University, Townsville

Ceccarelli DM, Jones GP, McCook LJ (2001) Territorial damselfishes as determinants of the structure of benthic communities on coral reefs. Oceanogr Mar Biol Annu Rev 39: 355-389

Ceccarelli DM, Jones GP, McCook LJ (2005) Foragers versus farmers: contrasting effects of two behavioural groups of herbivores on coral reefs. Oecologia 145:445-453

Davies NB (1978) Ecological questions about territorial behaviour. In: Krebs JR, Davies NB (eds) Behavioural ecology. Blackwell Scientific Publishers, Oxford

Diaz-Pulido G, McCook LJ (2002) The fate of bleached corals: patterns and dynamics of algal recruitment. Mar Ecol Prog Ser 232:115-128

Ferreira CEL, Gonçalves JEA, Coutinho R, Peret AC (1998) Herbivory by the dusky damselfish Stegastes fuscus (Cuvier, 1830) in a tropical rocky shore: effects on the benthic community. J Exp Mar Biol Ecol 229:241-264

Grant JWA (1997) Territoriality. In: Goudin JGG (ed) Behavioural ecology of teleost fishes. Oxford University Press, Oxford

Hata H, Kato M (2002) Weeding by the herbivorous damselfish Stegastes nigricans in nearly monocultural algae farms. Mar Ecol Prog Ser 237:227-231

Hata H, Kato M (2003) Demise of monocultural algal farms by exclusion of territorial damselfish. Mar Ecol Prog Ser 263: 159-167

Hay ME (1981) Herbivory, algal distribution and the maintenance of between-habitat diversity on a tropical fringing reef. Am Nat 118:520-540

Hay ME (1984) Patterns of fish and urchin grazing on Caribbean coral reefs: are previous results typical? Ecology 65:446-454

Editorial responsibility: Otto Kinne (Editor-in-Chief), Oldendorf/Luhe, Germany
Hixon MA (1980) Food production and competitor density as the determinants of feeding territory size. Am Nat 115: $510-530$

Hixon MA (1996) Effects of reef fishes on corals and algae. In: Birkeland C (ed) Life and death on coral reefs. Chapman and Hall, New York, p 230-248

Hixon MA, Brostoff WN (1996) Succession and herbivory: effects of differential fish grazing on Hawaiian coral-reef algae. Ecol Monogr 66:67-90

Hughes TP (1994) Catastrophes, phase shifts, and large-scale degradation of a Caribbean coral reef. Science 265: $1547-1551$

Hughes TP, Szmant AM, Steneck RS, Carpenter RC, Miller S (1999) Algal blooms on coral reefs: what are the causes? Limnol Oceanogr 44:1583-1586

Hughes TP, Bellwood DR, Folke C, Steneck RS, Wilson J (2005) New paradigms for supporting the resilience of marine ecosystems. Trends Ecol Evol 20:380-386

Lassuy DR (1980) Effects of 'farming' behaviour by Eupomacentrus lividus and Hemiglyphidodon plagiometapon on algal community structure. Bull Mar Sci 30:304-312

Lewis DM (1999) The distribution of territorial damselfishes in relation to the zonation of benthic communities on two inshore fringing reefs. MSc(Qual) thesis, James Cook University, Townsville

Marshall PA, Baird AH (2000) Bleaching of corals on the Great Barrier Reef: differential susceptibilities among taxa. Coral Reefs 19:155-163

McClanahan TR, Muthiga NA, Kamukuru AT, Machano H, Kiambo RW (1999) The effects of marine parks and fishing on coral reefs of northern Tanzania. Biol Conserv 89: 161-182

McCook LJ (1996) Effects of herbivores and water quality on the distribution of Sargassum on the Great Barrier Reef: cross-shelf transplants. Mar Ecol Prog Ser 139:179-192

McCook LJ (1999) Macroalgae, nutrients and phase shifts on coral reefs: scientific issues and management consequences for the Great Barrier Reef. Coral Reefs 18:357-367

Robertson DR, Sweatman HPA, Fletcher EA, Cleland MG (1976) Schooling as a mechanism for circumventing the territoriality of competitors. Ecology 57:1208-1220

Sala E, Boudouresque CF, Harmelin-Vivien M (1998) Fishing, trophic cascades, and the structure of algal assemblages: evaluation of an old but untested paradigm. Oikos 83: 425-439

Sammarco PW, Carleton JH (1981) Damselfish territoriality and coral community structure: reduced grazing, coral recruitment, and effects on coral spat. Proc 4th Int Coral Reef Symp 2:525-535

Santana LE (2001) Resource selection by territorial damselfish and their effects on coral and algal assemblages. Honours thesis, James Cook University, Townsville

Schoener TW (1983) Simple models of optimal feedingterritory size: a reconciliation. Am Nat 121:608-629

Steneck RS (1988) Herbivory on coral reefs: a synthesis. Proc 6th Int Coral Reef Symp 1:37-49

Steneck RS (1998) Human influences on coastal ecosystems: does overfishing create trophic cascades? Trends Ecol Evol 13:429-430

Wellington GM (1982) Depth zonation of corals in the Gulf of Panama: control and facilitation by resident reef fishes. Ecol Monogr 52:223-241

Wilson S, Bellwood DR (1997) Cryptic dietary components of territorial damselfishes (Pomacentridae, Labroidei). Mar Ecol Prog Ser 153:299-310

Submitted: May 23, 2005; Accepted: September 6, 2005

Proofs received from author(s): January 29, 2006 